\title{
Planning and Developing an Interactive Computerised Tutorial for Learning in Higher Education.
}

\author{
Roisin Donnelly \\ Technological University Dublin, roisin.donnelly@tudublin.ie \\ Michael Gorman \\ Technological University Dublin
}

Follow this and additional works at: https://arrow.tudublin.ie/ltcart

Part of the Educational Methods Commons, and the Online and Distance Education Commons

\section{Recommended Citation \\ This Article is brought to you for free and open access by the Learning Teaching \& Assessment at ARROW@TU Dublin. It has been accepted for inclusion in Articles by an authorized administrator of ARROW@TU Dublin. For more information, please contact arrow.admin@tudublin.ie, aisling.coyne@tudublin.ie, gerard.connolly@tudublin.ie.}

Donnelly, R. C. and Gorman, M. P. (1999) Planning and developing an interactive computerised tutorial for learning in higher education. Teaching In Higher Education, 4(3), 397. 1999.

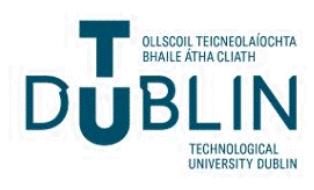




\title{
PLANNING AND DEVELOPING AN INTERACTIVE COMPUTERISED TUTORIAL FOR LEARNING IN HIGHER EDUCATION
}

\author{
Donnelly, R. C., \& Gorman, M. P. (1999). Planning and developing an interactive \\ computerised tutorial for learning in higher education. \\ Teaching In Higher Education, 4(3), 397.
}

\begin{abstract}
This paper describes how a researcher-lecturer in higher education attempted to identify, in her course, the constraints within which the teaching was required to operate. To better understand this particular problem area in her professional practice, it was necessary to take the student voice seriously and to suggest a possible solution to the problem.
\end{abstract}

It appeared that the 'Information Technology' module on a specific postgraduate course was particularly unattractive to the postgraduate students required to take it. The solution proposed was to develop and introduce into the module a form of innovation in course development, namely a Computer Assisted Learning (CAL) tool entitled 'Interactive Computerised Information Technology Tutor' (ICITT). The research process leading to the planning, development and introduction of the ICITT is the initial focus of this paper. The ICITT itself is then described in some detail in the latter part of the work.

\section{Introduction}

Researchers and lecturers in higher education encounter many educational problems in the course of their various curricular activities, which can strike at the core of their practice. Teachers of 'Information Technology' (IT) are no exception. This paper discusses one such problem experienced by a dedicated researcher-lecturer of 'Information Technology'.

The problem was one of low motivation and apparent 'Information Technology' fatigue experienced by students even before they embarked upon their IT module. The postgraduate module, which would provide the research sample, had been taught over a number of years by the researcher. The course module giving rise to the problem was entitled 'Information Technology/Management of Systems' and so provided the context for the research. The idea for the study emerged over the 4-year period during which the researcher-lecturer had been teaching the module on the course. Over that period of time, there was a gradual awareness that many of the students had strong feelings of resentment and dislike about the subject matter being taught. Each year there was the same experience. The researcher-lecturer found herself listening to the students' articulate their negative comments, and complaints about the module. These comments seemed to emerge even at the very commencement of the module. Indeed, some of the students seemed to have a long-standing aversion to the whole area of computing in general. Others said that it was a constant struggle for them to learn the important aspects of IT that were supposed to help them do their job. Initially, there was the concern that the present teaching was in some way 'boring' the students. However, after discussions with other teachers on the course, it was reassuring to know that, while this may have been a factor, it had been an ongoing problem 'year-in, year-out', since the course had begun; in fact, for years prior to this researcher-lecturer joining the course.

The literature agrees that frustration and anxiety are a part of daily life for many users of computerised information systems. These students were no exception. Some people encounter such serious cases of computer shock, terminal terror or network neurosis that they avoid using computerised systems (Shneiderman, 1987). Bertino suggested a reason why 
target audiences in computing in the past had a mistrust and fear of the technology. He stated that 'interfaces were incomprehensible, ambiguous and intimidating, leaving students feeling frustrated, insecure and even frightened' (Bertino, 1985). Research by McInerney et al. (1994) demonstrated the debilitating effect of computer anxiety on achievement in computer related learning. (For the purpose of this research, computer anxiety is defined as an affective response of apprehension or fear of computer technology accompanied by feelings of nervousness, intimidation and hostility.) The evidence from their study gives some support to the notion that increased experience leads to a diminution in computer anxiety. An important theme that emerged from examining the literature was the acknowledgement that technology decisions must be educationally driven, and tied to the ultimate goal of enhancing teaching and learning, along with the vital role of staff development as a key element in the success of any technology project. An initial literature search on the subject of Computer Assisted Learning (CAL) was conducted and was continued throughout the course of the research study.

The primary aim of this research study was to discover why students disliked the subject 'Information Technology', that is, to diagnose the problem. A secondary aim of the study was to use the knowledge gained from this process to design and develop a CAL package, entitled an 'Interactive Computerised Information Technology Tutor' (ICITT); in other words to attempt to solve the problem. This aid, which would assist students overcome their start-up problems with 'Information Technology', would, it was hoped, have a general use in the teaching of this course module in higher education institutions.

To carry forward the primary aim, it was decided that a two-stranded research methodology would be used. The researcher felt it was important to empirically establish the nature and extent of the problem from the students' perspective, while at the same time conducting a parallel analysis of the part that her own practice and that of colleagues might be playing in the problem. A number of informal interviews with students and colleagues were conducted as a means of gaining a basic understanding of the nature of the problem. At this time, the reason for the research was discussed with the students, along with details of what type of research was going to be conducted. This was to ensure that the students were satisfied with what was going to take place, and that their present attitude and interest in the subject were not affected in any adverse manner by the idea that they were going to be the subjects in a research study.

Secondly a student questionnaire was devised in which the students were asked a range of questions about their current and previous experiences with computers. A second questionnaire was devised in which the students were asked a series of questions about how they felt about the way in which they were being taught on their 'Information Technology' course. This second questionnaire, which it was intended would provide data to assist the researcher analyse her professional classroom practice, was complemented by a series of professional diary reflections in which the researcher recorded her thoughts and feelings about her practice.

\section{Diaries used in Research Study}

Diaries were used to document the effects of the research plan. Research by Burgess (1994), shows that keeping a personal journal is a valuable aid to professional growth. It was felt by the researcher that there would be power in the process of such personalised reflection.

The diary needed to be flexible and open to record the unexpected. The researcher needed to take notes on the action process planned, the effects of the action (intended and unintended), 
and the circumstances of and constraints on the action. Such observations were guided by the intention to provide a sound basis for critical self-reflection.

The diary used for this research contained personal, introspective accounts of anecdotes, observations, feelings, attitudes, motives and understandings in reacting to events and circumstances. It included both accounts of student development and self-monitoring of a change in teaching method. Basically, it intended to convey a feeling of what it was like to be there participating in the teaching itself.

For this study, the use of the diary proved very effective. It will be noted that the researcher frequently referred to quotes from the diary throughout the course of this study. For not only did it enable the researcher to monitor the overall results of the action plan, but at a deeper level, it helped her observe and understand the outcome of the other methods of data collection; namely, the two questionnaires and the interviews, discussed in detail presently.

\section{Some Initial Reconnaissance}

Built into this research was the belief that, if one finds dissatisfaction with what is already going on in one's practice, the confidence, resolution and means must be found to attempt to change it. Some intensive reflection and focused soul searching was embarked upon as a first step towards finding this confidence, resolution and means. An extract from the diary illustrates this.

Subject of Lecture: distributed computing systems

My second lecture this semester and the complaints continue (complaints which started at the beginning of the first lecture); not I hope about my ability to deliver the topics but, more on the 'vast amount of information that has to be covered' and 'no practical classes with which to experience the true meaning behind the theory'. I had continued to give handouts relevant to the subject this week, but apparently the class as a whole were not impressed. 'Too much boring theory to learn, and no exciting practical laboratory sessions' was the cry that echoed around the room again. I resolved to do something positive to amend the situation. I promised the class that I would speak with the senior lecturer of the course on the matter.

I realise that this subject matter can appear 'dry' and boring, but the course syllabus has to be covered. I try to overcome this with current and relevant examples from 'Computer Weekly' and other journals to which I am subscribed, but sometimes this just is not enough.

I have approached the senior lecturer and put forward the students' complaints. Seemingly this is a regular complaint every year with this course; it was agreed that there was a definite need to address this problem, so amendments are going to be proposed for the course next year. However, this will not in any way deal with the complaints of this year's class. Thus, the senior lecturer outlined a number of points that I was to convey to the students. This would, in some way, console them, and from my point of view, put a check on the complaints.

After only two lectures with this particular group, it became clear that the students were having major cognitive and motivational problems with 'Information Technology' as a subject. They seemed to be having anxieties about the amount of knowledge they were receiving. There seemed to be difficulties in internally assimilating it and there was a lack of time and opportunities in which to work with it in a practical way. There also seemed to be dissatisfaction with the teaching methodologies employed. Lecturers were boring. 
Even at this early stage of the research process 'visions' of a possible solution to the problem (a problem which was not yet clearly defined) began to be conceived in the mind of the researcher. Reflecting upon, '"Too much boring theory to learn, and no exciting practical laboratory sessions" was the cry that echoed around the room again', invited deliberations of how best to provide exciting laboratory sessions. Could a stimulating 'Computer Assisted Learning' package provide such 'excitement'? It seemed reasonable to employ information technology pedagogically in a teaching/learning situation in which it was also the subject to be learned.

Subject of Lecture: computer modelling and associated software packages

I am dissatisfied with this aspect of my current practice:

I feel that the students need much more interaction during the course of lectures--without becoming too side-tracked from the lecture material itself; I feel the interaction could come in the form of CAL, but I would need to more fully gauge my students' opinions on this. I could clarify certain technical areas of the course with the students through CAL, which may prove more successful than present. The main problem with lecturing to this group is that the majority of students have not worked extensively with computers and they are being asked to understand what are sometimes very technical issues.

At this stage, however, much only 'seemed' to the researcher-lecturer. The problem 'seemed' to be one of low motivation allied to 'Information Technology' fatigue and lack of confidence. The source of the problem 'seemed' to be founded in the areas of volume of knowledge and teaching/learning methodologies. The problem 'seemed' to be one that could be solved by the use of an appropriately designed Computer Assisted Learning package. More concrete research steps were needed to confirm these impressions.

\section{Interviewing for a Deeper Understanding}

In order to understand the full nature of the disapproving comments the students were making about the course, the researcher first decided to discuss the matter informally with colleagues and students. These informal interviews, it was felt, would not only contribute to a fuller understanding of the nature of the problem, but would also provide a foundation of information from which subsequent data gathering instruments could be developed.

Two informal interviews were arranged with a sample of the students to further measure the extent of the problem. These qualitative approaches (interviews and diary reflections) would be supplemented later by the use of the quantitative research method of questionnaires. The questionnaires would be used to confirm the 'feelings' and opinions expressed by the students over the previous four years of taught classes. It was felt necessary to empirically prove or disprove what the students had been verbalising about the course.

The essence of the true feelings of the students was captured in the informal interviews with colleagues and students. Analysis of the interviews indicated clearly that the students thought 'Information Technology' was very difficult and unexciting as it was presently being taught. They stated that the course confirmed some of the negative feelings they had about 'Information Technology' even before the course commenced. They said they had came on the course with feelings of anxiety while at the same time hoping the course would provide the 'magic' answer. Higher Education would have more to offer in terms of their deeper understanding of 'Information Technology' than had their previous educational experiences. Sadly, they said, their early experience of the course was more of the difficult same. There were transparent implications for professional teaching practice in these findings. A factor 
which kept cropping up in these interviews with students was how to stimulate interest in the subject for the students.

In the interviews with colleagues a number of important issues were raised in the form of questions. Was the problem solely down to the non-practical teaching techniques? Was there a need to change how the subject was being taught? Was there a fundamental philosophical defect in the curriculum in that it was too theory orientated and not nearly practical enough? One colleague commented that in higher education our business is academia; much of the teaching and learning of 'Information Technology' is practical in nature and thus more suited to 'Further Education'.

\section{Questionnaires for Deeper Understanding}

Reflecting on these issues together with further deliberation on the suitability of the lecture methods being used (with the aid of the diary) a decision was taken to empirically investigate, with questionnaires, the reasons for the students' current dislike of IT. A second closelyrelated reason for using questionnaires was to evaluate the merits of introducing a CAL element into the course. Two distinct questionnaires were developed to investigate these factors. The interviews indicated important areas for improvement; areas that were personally controllable by the researcher and that could be changed. The outcomes from this research could be translated into positive action. The actions planned for these issues were deliberate and controlled. The plan was to transform all the students' learning capacity by assisting them to remove this mental block of lack of confidence in 'Information Technology'.

The questionnaire methods were combined with a teaching diary to test and challenge the emerging interpretations. The rigour of this study was improved substantially by integrating the literature search as the study continued, with the data collection and interpretation. There was an intention to work with multiple information sources, preferably independent ones (classroom observations, informal listening to students' complaints, interviews with students and colleagues, reflective diaries and two structured questionnaires). This was so because there was the intention to use the similarities and differences between the data sources in order to increase the accuracy of the information. This can arguably be called dialectic. It is similar to what is often called triangulation in research (Jick, 1979).

Having investigated the general notion of the students' low interest levels in IT within the informal interviews, and having decided that the problem was capable of being tackled effectively by this researcher, more detailed research was embarked upon. Armed with the qualitative data from the informal interviews reinforcing the research question, the full study got underway. Quantitative data was obviously going to be strong element of this research. The two questionnaires were used to clarify the much-needed specific points of contention that the students had about learning about 'Information Technology'.

For the purposes of this research, the crux of the matter was to discover why the students were coming into the course with negative preconceptions and disapproving attitudes towards IT and to discover the extent to which the curriculum processes (lecture methods, virtual absence of practice, the underlying philosophy of academia) were contributing to these problems. Opportunities for change would hopefully emerge as the discovery process unfolded.

The first step was to plan to analyse the problem. This researcher had identified the problem of the students disliking their 'Information Technology' module, and this was regarded as the primary situation to be remedied. The wider constraints around this issue were not allocated the same priority. Examples of such are the organisation, resources, time-tabling of the 
'Information Technology' module, along with other teachers' attitudes to CAL. The second step was to suggest and lay out a strategy to resolve this problem.

Acting to implement the research plan, it was noted in the diary at the time: 'I feel very strongly that to diagnose and explore this problem situation at this time is the correct thing to do. Unlike previous years, I am now 100\% committed to taking curative action to ensure that improvements in how IT is taught will occur for this year's class.' Elliott (1981) affirms that there is a world of difference between identifying a problem situation and doing something about it. Following the cycle of reviewing relevant literature and conducting informal interviews it was concluded that the time was now ripe to use structured questions as a method of data collection, which would point to the development of a solution. It was felt that using questionnaires would be advantageous to this study because they would provide a useful method of obtaining information in a structured format.

The sample for the study consisted of 38 postgraduate students of whom 24 (63\%) were male and $14(37 \%)$ were female. Their ages ranged from 20 to 35 years. The plan of action was implemented by distributing the two questionnaires. At that point in time the following was written in the diary:

\section{Subject of Lecture Object Orientation}

I have distributed the two questionnaires for my main study. I hope data analysis of these questionnaires will give me further insights into this whole problem area and into ways in which CAL can help me resolve it.

The types of 'evidence' that could be collected to help to make some judgement about what was happening had already been considered. The instruments were thus developed quite quickly. Three weeks into the course, the first questionnaire was distributed. This questionnaire, titled 'Computer Assisted Learning/Multimedia Questionnaire' was designed to explore the students' pre-course experience and pre-course attitudes to 'Information Technology', and their experience and attitudes towards CAL. Two weeks later, to discover what the students thought about the teaching methods of the course, along with the students' preferred learning methods, a 'Traditional Teaching and Learning Methods' questionnaire was then distributed to the class. Full student participation was a vital requirement of this study.

\section{Computer Assisted Learning/Multimedia' Questionnaire}

This was quite an extensive questionnaire, made up of 57 questions. These questions were grouped into six sections. Although, arguably a lengthy questionnaire, as Hoinville \& Jowell (1977) contend, the appearance of a questionnaire is more important than its length.

The first section required simple personal details on the students' present learning. This was followed by a section asking how important computers are to the student. In this 'Importance of Computers' section, questions were asked in regard to computers being important to one's future career and whether the students do most of their learning conventionally, or on a computer. The students were also asked to rate their current knowledge and level of competence of using computers.

In the third section, an attempt was made to gauge the students' previous experience with computers. The students were asked to describe as best they could their total amount of experience with computers. Next were two separate sets of questions to discover, firstly, the students' opinions on CAL, 'Computer Assisted Learning' and secondly, their assumptions about multimedia, 'General Attitudes to Multimedia'. 
In the 'Computer Assisted Learning' section, the students were asked if they had ever used any CAL products before, and if so in what capacity. A central question investigating the benefits of CAL was broken into sub-questions asking how they had previously used CAL.

I have previously used CAL:

To improve my work skills

To experiment for my personal growth

To learn for the sake of my own learning

To keep one step ahead of the other students

To keep current in my field of study

To enhance course content

To better meet individual learning needs

To offer better quality service in my work

To empower me to learn independently

To renew my enthusiasm for work

To explore the students 'General Attitudes to Multimedia' a range of questions were put which provided data on their multimedia preferences, their previous experience with multimedia projects, how effective multimedia is/was to their learning in general and their learning of 'Information Technology' in particular, and the direction they see their use of multimedia developing over the next number of years.

Finally, in a section entitled 'General Attitudes to Computers', a battery of statements were set out to which students were asked to indicate the extent of their agreement. These included:

- Knowing how to use computers is a worthwhile and necessary skill

- I feel confident with my ability to learn about computers

- Working with a computer makes me nervous

- I use my knowledge of computers in many ways

- I like using computers in my work

- I wish I could use computers more frequently at the university

- Once I start to work with the computer, I find it hard to stop

- Computers make me feel inadequate

The section concluded with an optional open-ended question allowing the students to provide further details on their views on CAL. These mature respondents would probably have their own ideas concerning the nature and degree of CAL in teaching IT in third level education, and this, in turn, could possibly have an influence on the way they answered the earlier questions.

One of the most significant findings to emerge from the analysis of the responses was that $50 \%$ of the students regarded themselves as novices in the use of computers prior to coming on the course and a further $13.2 \%$ indicated that they had never before had hands on experience of computer technology. The researcher now felt that these results gave significant weight to the students' vocalised aversion to the subject matter at the beginning of the course.

Of the students sampled, $44.7 \%$ indicated that up to this point they had not used any CAL products; that is, they had not used CAL products before coming into higher education nor since entering higher education. 55\% of these students (students who had not used CAL products before) attributed not having used CAL products since coming into higher education 
as due to the quality of the software presently available. Of the $55.3 \%$ of students who had used CAL $16 \%$ indicated they found it provided opportunities to experiment for personal growth, only $15 \%$ found it improved their work skills, $14 \%$ indicated that CAL assisted in keeping them current in their field of study and $13 \%$ testified that they benefited in so far as CAL facilitated their individual learning needs. Figure 1 illustrates these results.

FIG. 1. Q. 27 What benefits did CAL give you?

$\begin{array}{ll}\text { Offer better quality service in work } & 10 \% \\ \text { Empower me to learn independently } & 9 \% \\ \text { Renew enthusiasm for work } & 5 \% \\ \text { Improve work skills } & 15 \% \\ \text { Experiment for personal growth } & 16 \% \\ \text { Learn for the sake of my own learning } & 2 \% \\ \text { Keep one step ahead of other students } & 5 \% \\ \text { Keep currently in field of study } & 14 \% \\ \text { Enhance course content } & 11 \% \\ \text { Better meet individual learning needs } & 13 \%\end{array}$

Number of students $n=38$

\section{'Traditional Teaching and Learning Methods' Questionnaire}

It was decided that this questionnaire could be used as a means of gathering the students' views about their preferred teaching and learning methods. This data collection method allowed the researcher to focus on specific areas that were of concern to the students. It was designed to enable them to become more aware of their own learning style (their relative strengths and weaknesses), and to be able to monitor and evaluate their effectiveness as learners. The questionnaire allowed the researcher-lecturer to quantify the students' observations, interpretations and attitudes to the present mode being used to teach them. A copy was distributed to each of the 38 students $(n=38)$, at the beginning of a lecture.

This questionnaire consisted of 25 questions and was designed to be completed by the students at whom the study was directed. It could be completed fairly quickly and allowed each student the opportunity to express an opinion which he/she might otherwise not have had the chance to articulate. This was felt to be important because there was a need to know the way that the students thought and approached the learning process in general.

There were two sections in this questionnaire, namely 'Teaching Methods' and 'Learning Methods'. A series of topics relating to the former opened the questionnaire, and a further set dealt with the latter. The researcher was interested to find out what learning styles the students' preferred, along with how strong a desire existed for a change in teaching methods within the class. The researcher had to ask herself whether having the present mode of teaching evaluated by students would highlight any discrepancies in her teaching and thus contribute to the improvement of the overall teaching performance of the subject. It was also felt that any dissonance so generated could be a driving force for change; that change could be a guarantee to the students of an acceptable standard of competence in the teaching.

The need for the researcher-lecturer to increase her insights into her teaching strengths and weaknesses, and the felt need to improve her teaching skills provided a focus for analysing this particular questionnaire. To facilitate this, the questionnaire was analysed under critical comment headings.

Students were generally highly critical of the teaching methods used on the course. For example, $78 \%$ strongly disagreed that the teaching was clearly presented with only $3 \%$ 
strongly agreeing. Reinforcing this, $84 \%$ of the students strongly disagreed that the lecturer delivered the lectures in an interesting and understandable way with only $13 \%$ strongly agreeing (3\% undecided). Questions which aimed to explore the source of this discontent revealed that the low level of student activity and few practical illustrations were important factors. For example, $89 \%$ of the students strongly disagreed that the lecturer reinforced ideas with illustrations and $66 \%$ strongly disagreed that the lecturer encouraged classroom interaction. From a learning perspective most students on the course were fairly confident in their personal learning abilities. Most (76\%), however, indicated that they preferred to learn on their own but in an interactive way. This empirical evidence went a long way in supporting the information that had emerged from the earlier informal interviews and the personal reflections of the researcher-lecturer.

Open-ended questions at the end of the questionnaire also revealed some interesting comments. When asked, for example, to detail their overall impression of the teaching they received, $68 \%$ of respondents indicated that they needed more practical experience to reinforce the theory received in lectures. It is interesting to reproduce some of these comments:

...a more orderly well-planned and structured synopsis in which basic principles can be emphasised is needed. If the course was more practical in nature, this would contribute more effectively to my understanding of the topics.

More recapping and repeating of important points will guarantee better understanding of this subject.

Relating important points to current examples and practical applications will make the lectures more interesting and hold my attention more.

\section{Reflections}

Critical reflection was one of the important defining features of this research study. It encouraged this researcher-lecturer to be reflective of her own teaching practice in order to enhance the quality of education for both herself and her students. In other words, this teacher decided to consistently and relentlessly intervene in her own practice, to be aware of her own practice, to be critical of that practice, and using this self-critical awareness to be open to a process of change and improvement of practice. It can be stressed at this juncture that this should be a continuous activity. The teaching diary was used as the chief source of reflection in this study and it also provided the mechanism for integrating the various aspects of the research process.

I have had opportunity to perform a basic content analysis on the first questionnaire returns and I am completely satisfied on reflection that my original diagnosis of the problemsituation was spot-on. The students' replies to my questions about the effectiveness of the lecture method alone to deliver the IT course material mirror the problem that I depicted in my research study.

There was a desire to introduce CAL to the lessons by structuring learning, motivating learning, encouraging activity and independence in learning and establishing interpersonal relations conducive to learning. The researcher had planned from the outset to make changes to the way the course was taught, but these changes would be based on the information gathered from the interviews and the students' questionnaires. 
If possible, this research will be used to encourage more positive attitudes to learning 'Information Technology' in Third Level Education generally by improving the present practice of teaching it, namely the lecture-based approach. The development of an 'Interactive Computerised Information Technology Tutor' (ICITT) will provide a concrete mechanism for achieving this.

\section{ICITT Development}

The production of a prototype CAL package (ICITT) would therefore provide a much-needed practical element to the 'Information Technology' module previously discussed. By using ICITT, the students would be able to gain hands-on experience of the subject matter.

The development of ICITT recognises that different learners may wish to use such CAL materials for different purposes and in different ways, for example, as new learning in the subject area or as a refresher course or for studying for an examination. Using ICITT, the students can study any available subject area they wish as there will be a range of IT skills available. They can also study when and where they find most convenient, for example, working in the laboratories in their own time to supplement lectures, and at their own individual pace. This may help as an incentive to students to enjoy the subject. Existing subject matter which bored the students can now be rejuvenated to help increase their overall understanding and learning capabilities in IT.

\section{The ICITT System}

ICITT was planned and developed as an interactive computerised assessment system in order to provide an alternative learning experience for students and to achieve a more efficient use of teaching time. It was not designed to replace specialised subject area teaching. Instead, it supplements paper-based learning, but is more fun than a book, and appears much better visually. It can be described as a 'learner support environment', since it assumes that the intelligence resides largely with the student and thus it concentrates on providing optimal conditions for learning. It makes use of interactive CAL, by promoting active learning in which there are high degrees of participation and involvement by the student.

The objectives behind the planning and subsequent development of ICITT are as follows: to aid management of learning, testing, tutoring, exercising, dissemination and archival of material. One of the important functions of ICITT is that the computer is integral in the management of the learning process. As a result of ICITT's record-keeping ability (and analytical power), it can monitor a student's progress through the course of the instructional material.

The ICITT system consists of four inter-linked components:

- the core ICITT system;

- modules, each containing a database of specialised questions with answers and explanations;

- an on-line tutorial for beginners to the system;

- the fully context-sensitive (to specific subject areas) multimedia hypertext help system which contains high quality images, and links to the questions in the associated database module. This is a useful and interesting way to revise the material quickly.

The most significant difference between ICITT and previous methods of classroom instruction (lectures) for the IT module is that in ICITT the student is interacting with a computer rather than with other peers or teachers. Each student is required to respond to each question. The core ICITT system is programmed to react to each response with an individualised message depending on the response. Learners answer in the privacy of their 
interaction with the computer terminal. An ICITT lesson can assess a student's understanding only by asking pertinent questions and monitoring responses.

A further advantage of ICITT is that it is individually paced. Each student can work at an appropriate level of difficulty and proceed in the lesson at a pace that is appropriate for them. Such individualised instruction is a significant feature of CAL (Steinberg, 1984).

While a full and comprehensive evaluation of the package will take some considerable time, early evaluations indicate that students are able to interact with ICITT and their abilities are amplified, not impeded, by using it. The reasons for this are outlined. ICITT is very adaptable to students' working patterns as it can be used wherever there is a suitably connected workstation and at times when the laboratories in which it exists is accessible. Provided suitable access arrangements can be made, workstation rooms can be used for many more hours in the week than lecture theatres and a shift from lectures to this CAL package is enabling more students to be taught without more lecture theatres. Even where ICITT is used as a supplement to conventional teaching, it is mitigating the negative effects of larger class sizes through the interaction it offers.

It should not be overlooked that learning with computers is often fun! ICITT is proving to be both motivating and stimulating. The essential pedagogical idea behind the production of this CAL package ICITT, was that it should open up new opportunities for students to learn. ICITT provides a new innovative approach to the teaching of 'Information Technology'. It will contribute further in assisting students to develop understanding and skills in 'Information Technology', and become more interested in the course material which they are required to learn.

\section{Conclusions}

This research study has been one whose solution will make a contribution to the body of organised knowledge in the use of CAL in higher education. The solution of the problem should make a difference to educational practice. Other educators could be interested in the findings. The problem is one that can lead to new problems and so to further research. The evaluation of ICITT is currently ongoing and will be the subject of a later paper.

\section{REFERENCES}

BERTINO, E. (1985) An Introduction to Human Computer Interaction (Wokingham, Addison-Wesley).

BURGESS, R.G. (1985) Issues in Educational Research (Brighton, Falmer Press).

ELLIOTT, L. (1991) Action Research for Educational Change, Developing Teachers and Teaching (Buckingham, Open University Press).

HOINVILLE, R. \& JOWELL, R. (1977) Survey Research Practice (London, Heinemann).

JICK, T.D. (1979) Mixing qualitative and quantitative methods: triangulation in action, Administrative Science Quarterly, 24, pp. 602-611.

MCINERNEY, V., MCINERNEY, D.M. \& SINCLAIR, K.E. (1994) Journal Educational Computing Research, 11 (1), pp. 27-50.

SHNEIDERMAN, B. (1987) Designing the User Interface, Strategies for Effective Human-Computer Interaction (New York, Addison-Wesley Publishing Company, Inc.). 
STEINBERG, E.R. (1984) Teaching Computers to Teach (Hillsdale, Lawrence Erlbaum Associates). 